\title{
Dialética negativa e educação: apontamentos a partir da teoria crítica de Herbert Marcuse ${ }^{1}$
}

\author{
Vivian Baroni²
}

\section{Resumo}

Como parte da herança hegeliana, a obra de Marcuse sempre foi marcada pela negatividade característica da dialética. Nestes termos, a abordagem dos problemas formativos procura mostrar os dois lados da realidade social, o que revela uma teoria preocupada não somente com a compreensão da realidade, mas com a emancipação do que é estabelecido de antemão. O presente artigo busca na análise da obra A ideologia da sociedade industrial: o homem unidimensional, mapear, mesmo que brevemente, os elementos principais que caracterizam a teoria de Marcuse no que se refere à abordagem dialética da sociedade, assim como as implicações dessa abordagem para se pensar uma educação crítica.

Palavras-chave: Dialética hegeliana; Herbert Marcuse; Educação estética.

\section{Negative dialectics and education: notes from the critical theory of Herbert Marcuse}

\section{Abstract}

As part of the Hegelian heritage, Marcuse's work has always been marked by the negativity characteristic of the dialectic. In these terms, the approach to training problems seeks to show both sides of social reality, revealing a theory concerned not only with the understanding of reality, but with the emancipation of what is established beforehand. The present article seeks to analyze the work of the ideology of industrial society: the one-dimensional man, to map, even briefly, the main elements that characterize Marcuse's theory with regard to the dialectical approach of society, as well as the implications of this approach for if you think about critical education. Keywords: Hegelian dialectic; Herbert Marcuse; Aesthetic education.

\section{Considerações iniciais}

Para Marcuse, a apreensão da realidade não deve jamais se circunscrever ao que é dado de antemão; é preciso transcender as condições reificadas que dão a aparência do real para assim vislumbrar a totalidade dos elementos, positivos e negativos, que configuram a realidade estabelecida. Para isso, Marcuse procura ressaltar a importância da dialética como ferramenta teórica essencial no reconhecimento da sociedade estabelecida, dos mecanismos de conservação e perpetuação do status quo repressivo, assim como da necessidade de transcendência dessa realidade. É na observância da negação ao que é estabelecido, e na afirmação da necessidade de superação desse estado que se criam as condições para a emancipação social.

\footnotetext{
${ }^{1}$ Pesquisa financiada através de bolsa PROSUC/CAPES.

2 Universidade de Passo Fundo, Passo Fundo, vivianbaroni@hotmail.com 
No livro A ideologia da sociedade industrial (1978), Marcuse procura demonstrar esses dois movimentos da dialética na análise da sociedade sob a égide do capitalismo monopolista. Buscando demonstrar os mecanismos utilizados pela sociedade estabelecida na manutenção do estado de sujeição do homem, Marcuse remonta sua abordagem ao conceito de razão, mostrando passo a passo a dissolução do negativo no positivo e a derrocada do pensamento negativo, fator essencial de uma dialética crítica da razão. Por sua vez, a falta do movimento de negação da razão acaba interferindo diretamente nas condições materiais da sociedade, como na noção de tecnologia e no conceito de educação positivista e unidimensional.

Contudo, para Marcuse a negação ainda é conservada em uma dimensão que não pôde ser absorvida pela sociedade: a dimensão estética. Nela é possível vislumbrar tanto a negação da realidade quanto a afirmação da libertação, o que infere as possibilidades formativas de uma educação estética para o resgate da razão crítica. Ao nos apropriar da negatividade dialética que jorra da teoria estética de Marcuse, é-nos permitido repensar os problemas formativos contemporâneos sob um novo olhar, capaz de renovar a abordagem educacional pela via da superação do que é dado de antemão. Nesse sentido, o presente ensaio pretende estudar, mesmo que brevemente, a noção de razão dialética no livro A ideologia da sociedade industrial, procurando mostrar os desdobramentos formativos advindos da noção dialética de razão segundo a obra de Marcuse.

Para tanto, desenvolveremos o artigo em três partes principais. Na primeira, exporemos as bases pulsionais que sustentam a análise da sociedade industrial realizada por Marcuse. Nos focaremos no diálogo entre Marcuse e a psicanálise freudiana, demonstrando como os conceitos de sublimação e dessublimação refletem aspectos emancipatórios e repressivos das pulsões na dinâmica com a sociedade avançada. Na segunda parte, demonstramos como a prevalência de Logos sobre Eros resultou no desenvolvimento de um a priori tecnológico que antevê a natureza como objeto de controle. Tal fato culminou na regulação social através de necessidades adquiridas ou falsas necessidades. Por fim, mostraremos como a estética na obra de Marcuse representa a tomada de consciência e, ao mesmo tempo, a negação das condições existenciais repressivas, permitindo uma quebra na estrutura da dominação em prol da realização da potencialidade das coisas e dos homens. Nessa acepção, pode-se falar da educação estética como aquela que possibilita aos sujeitos transcenderem a esfera cotidiana da consciência coisificada, gestando uma 
consciência crítica capaz de dar conta do complexo processo de emancipação.

\section{Eros, Logos e civilização: a dessublimação repressiva}

Uma das marcas principais da fase inicial de Marcuse é o livro Razão e revolução (1972), publicado em 1940. Nesse livro, que esboça a origem da teoria social e esclarece importantes conceitos para a perspectiva crítica, Marcuse aponta para a importância do pensamento hegeliano na sua filosofia. Resumidamente, pode-se extrair dos escritos hegelianos dois conceitos chave utilizados por Marcuse: o de razão, entendida aqui como a faculdade humana que se manifesta no uso completo feito pelo homem de suas potencialidades; e o de negatividade, núcleo da dialética. Nos estudos de Marcuse, torna-se evidente a marca da dialética hegeliana: a cisão da realidade em opostos e a conciliação desta cisão em uma síntese superior, dada através da razão.

Contudo, a noção de separação dos opostos, a bidimensionalidade do mundo encontrada em Hegel já fazia parte da filosofia antiga, como é o caso da dialética platônica, que refletia a concepção de um mundo antagônico em si, "afligido pela necessidade e pela negatividade, constantemente ameaçado de destruição, mas também um mundo que é um cosmo, estruturado de conformidade com as causas finais" (MARCUSE, 1978, p.127). O movimento dialético compreende a tensão crítica entre o "ser" e o "dever ser" como condição ontológica pertencente à própria estrutura do Ser. Nessa perspectiva dualista a razão pode ser compreendida como poder subversivo, negativo, que estabelece "a verdade para os homens e as coisas - isto é, as condições nas quais os homens e as coisas se tornam o que são" (MARCUSE, 1978, p.125).

Todavia, na sociedade industrial avançada o que impera é uma total transmutação desta concepção de razão. Sob a égide do positivismo, o conhecimento passa a se basear no domínio racional do mundo natural sob o aspecto da necessidade objetiva. Nesse sentido, a ciência é vista como o campo do relativismo teórico, área da qual estão excluídos os juízos de valor. Isso ocasiona a oposição entre razão e emoção, e que mais tarde reflete a separação entre as ciências da natureza e a metafísica. Segundo Marcuse, tal fato se dá essencialmente por meio da separação realizada pelo pensamento científico entre Eros e Logos. Em Marcuse, o termo Logos pode ser visto como a percepção do mundo como um todo organizado, e ao mesmo tempo

$$
\text { Periódico Horizontes - USF - Itatiba, SP - Brasil - e019037 }
$$


discurso que explica a ordem do mundo. Quanto a Eros, sua definição aproxima-se do conceito freudiano, como impulso que designa as pulsões de vida e autoconservação, no qual a energia potencial, essencialmente de caráter sexual (não-genital) é constituída pela libido e regida pelo princípio do prazer.

Desde a antiguidade as modalidades do Ser podem ser vistas como categorias de movimento, sendo que o Ser finito é também o Ser incompleto, buscando incessantemente a construção de uma realidade distinta daquela composta por antagonismos. A resposta a tão angustiante situação é obra de Eros e Logos, unidades do negativo e do positivo, da criação e da destruição: "nas exigências do pensamento e na loucura do amor está a negação destrutiva dos estilos de vida estabelecidos. A Verdade transforma as modalidades de pensamento e da essência. Razão e Liberdade convergem" (MARCUSE, 1978, p.129). A construção da verdade era dada através da mediação progressiva dos antagonismos, o que implicava um conceito de razão não absoluto (tal como o apregoado pelo positivismo), mas sim constituído por uma multiplicidade de conceitos que se auto completavam, sendo Eros o conhecimento erótico e Logos o conhecimento lógico.

Como afirma Nicolas (1971, p.122-123), a visão otimista de Eros e Logos evoluindo juntos em negatividade para assim animar a matéria em um movimento ascendente para formas de realidade superiores, logo se viu ameaçada pela realidade da existência e da provisão material da vida, fazendo com que a dimensão de Logos prevalecesse sobre Eros. Sendo assim, a ruptura dessa frágil relação, que poderia fundamentar um conceito ontológico ao erotismo, é consumida pouco a pouco no decorrer da conquista do mundo pelo racionalismo. Dessa nova realidade devem ser distinguidas duas fases: 1) na primeira, o princípio da realidade suprime o princípio do prazer, utilizando sua energia em benefício da produtividade. Nesse caso, Eros só pode ser sublimado repressivamente, aparecendo como além do princípio da realidade, como princípio de destruição ontológica; 2) a segunda fase se distingue pela destruição dessa sublimação: com a racionalidade crescente do sistema produtivo, a sociedade pode permitir-se dar mais do que anteriormente, pois seus interesses já foram plenamente incorporados pelos sujeitos. Daqui em diante, é o princípio do prazer que absorve o princípio da realidade, conduzindo a uma dessublimação repressiva; a sexualidade é liberalizada, porém, continua atada à realidade tecnológica.

O conceito de dessublimação é um dos aspectos mais importantes do pensamento Periódico Horizontes - USF - Itatiba, SP - Brasil - e019037 
marcuseano, sendo que sua origem pode ser encontrada no conceito de sublimação freudiano. A sublimação consiste em um processo no qual o sujeito desvia as pulsões de seus alvos primários para outros mais elevados e socialmente aceitos. A arte é a dimensão por excelência da sublimação: nela a pulsão não é reprimida, mas sim ampliada. A sublimação pode ser considerada como uma das vicissitudes das pulsões e representa a restrição quanto à possibilidade de satisfação pulsional imposta pelo choque com o mundo exterior, pois o surgimento da civilização só pode advir com o adiamento da satisfação pulsional e, consequentemente, da inibição dos fins sexuais imediatos.

O processo de sublimação surge também como a resolução do complexo de Édipo, em que aparece o abandono da sexualidade polimórfica, o estabelecimento da sexualidade genital através da sublimação das pulsões primárias e a formação do Superego e do ideal de Ego. No conflito que estrutura a formação do Superego acontece uma internalização das imposições e restrições sociais e a introjeção das exigências do princípio da realidade. Nesse caso, e considerando que a sublimação se apresenta como uma imposição da sociedade, ela preserva a consciência da repressão, e, portanto, a revolta das pulsões contra o princípio da realidade (PISANI, 2004, p.34).

Já a dessublimação repressiva, se refere à retirada dos impedimentos das pulsões e a sua realização de forma imediata, que se mostra através de uma dessublimação da esfera sexual. Através da liberalização da sexualidade genital - não de Eros - substitui-se a satisfação mediada pela arte, por uma satisfação imediata, que obscurece a tomada de consciência e enfraquece a revolta das pulsões contra o princípio da realidade. Dessa maneira, a dessublimação repressiva da sexualidade se dá de uma forma que não se opõe ao princípio da realidade, mas o mantém. Ao invés de haver um restabelecimento da libido polimórfica e da energia erótica de Eros, há uma intensificação da sexualidade genital repressiva.

\section{Da dessublimação repressiva à razão unidimensional: a noção de técnica na sociedade avançada}

Nesse contexto, Eros acaba por se tornar unicamente força erótica dessublimada, enquanto que Logos, mais manejável, toma importante lugar de estudo na filosofia ocidental, 
fazendo com que a perda de contato com o real seja diretamente relacionada ao desenvolvimento da lógica formal. O desenvolvimento da lógica formal, ligada à utilização de instrumentos para o controle e calculabilidade universal, acaba tornando necessária a eliminação dos antagonismos e das contradições do pensamento a fim de dar materialidade às unidades variáveis no complexo processo da sociedade e da natureza (MARCUSE, 1978, p.137). O desenvolvimento extremo dessa lógica vai levar à ênfase nas ciências exatas e no operacionalismo.

Na racionalidade moderna, as substâncias teleológicas, cada qual com um sentido e um propósito perpassando e ordenando as partes de que é composta, são substituídas pela razão científica, em que os objetos da experiência são divididos em componentes mensuráveis e as relações entre esses componentes são explicadas casualmente, como um maquinário natural. Conforme Feenberg (2012, p.144), essa nova concepção de razão passa a ser a ciência a priori, a pré-condição do seu modo de experimentar e compreender o mundo, e que se estrutura através de duas características essenciais: a quantificação e a instrumentalização. Embora existam valores que não podem ser colocados na esteira da quantificação, correlato à realidade quantificada da ciência, há um mundo interno no qual tudo o que é relacionado a valores pode se refugiar.

O que resta, o mundo objetivo despido de qualquer atributo valorativo, é exposto ao controle instrumental irrestrito. No entanto, esse instrumentalismo é inocente até certo ponto: a quantificação permite chegar a resultados precisos. A inocência da ciência é perdida somente quando as possibilidades de controle instrumental disponibilizadas pela ciência a priori são exploradas em larga escala pela tecnologia. O a priori da ciência permanece e torna possível sua apropriação pela teoria e prática racionais. Dessa forma, "a conexão entre ciência, tecnologia e sociedade é a forma a priori da experiência por elas compartilhada" (FEENBERG, 2012, p.144).

Essa confluência da tecnologia com a sociedade se dá efetivamente durante o capitalismo, que somente funciona perfeitamente quando pode dominar com certa margem de liberdade os recursos técnicos, assim como aos homens e a natureza, de forma que "a racionalidade e a manipulação técnico-científica estão fundidas em novas formas de controle social" (MARCUSE, 1978, p.144). Tal fato acaba por culminar fatalmente na construção repressiva da subjetividade, corporificada em uma forma de pensar e agir que, baseando-se na 
racionalidade tecnológica, torna o pensamento imune à contradição. Nas palavras de Marcuse, “o pensamento e o comportamento expressam uma falsa consciência, reagindo à preservação de uma falsa ordem dos fatos e contribuindo para ela" (1978, p.143).

O fato de as faculdades mentais serem direcionadas por modelos de pesquisa espelhados na lógica formal tende a tornar o pensamento livre dos elementos que permitem a negação da realidade estabelecida. Com isso, o esforço conceitual para manter a tensão entre o que "é" e o que "deve ser", para subverter o universo da locução em nome de sua própria verdade, é eliminado de um pensamento que dever ser exato e objetivo (MARCUSE, 1978, p.139). A bidimensionalidade da razão é abolida, e no seu lugar surge uma forma de pensar unidimensional, prejudicando o aparecimento da resistência legítima. Dessa maneira a realidade assume uma lógica e verdade própria, reafirmando o caráter irrevogável da realidade estabelecida. No entanto, o esforço para compreender a realidade enquanto tal e transcender os seus limites pressupõe uma lógica diferente, uma verdade contraditória, que se aglutinam em torno dos modos não-operacionais de pensamento (MARCUSE, 1978, p.141).

Ora, se a racionalidade tecnológica que permeia a ciência é derivada da dominação imposta aos homens e à natureza, logo, o aumento da produtividade resultante de um processo rígido de controle das forças produtivas já não leva ao aumento das contradições, que por si, poderiam resultar em uma situação revolucionária. Mais do que isso, para Marcuse, o caráter repressivo da tecnologia não advém somente de seus usos específicos feitos pelo aparato tecnológico, pois seu caráter totalitário é condição inerente à própria ideia de razão. Frente às particularidades totalitárias dessa sociedade, a noção de neutralidade da tecnologia torna-se insustentável: "a tecnologia não pode, como tal, ser isolada do uso que the é dado; a sociedade tecnológica é um sistema de dominação que já opera no conceito e na elaboração das técnicas" (MARCUSE, 1978, p.18).

Desta forma, temos o seguinte resultado: de um lado o crescente desenvolvimento da ciência e da tecnologia trazem para a sociedade inúmeros avanços que permitem a melhoria qualitativa da vida e a diminuição do tempo de trabalho. Por outro, a crescente mecanização acaba por se aliar ao sistema produtivo capitalista e passa a atuar como principal instrumento de repressão: na esfera da produção dissemina formas de trabalho alienado, enquanto que na esfera cultural, trabalha para constituir repressivamente a subjetividade individual em prol da

$$
\text { Periódico Horizontes - USF - Itatiba, SP - Brasil - e019037 }
$$


manutenção do sistema produtivo.

Pode-se dizer que a forma como a sociedade organizou o aparato tecnológico demostra seu caráter totalitário. Segundo Marcuse, "uma falta de liberdade confortável, suave, razoável, democrática prevalece na civilização industrial desenvolvida, um testemunho do progresso técnico" (1978, p.23). No diagnóstico marcuseano a liberdade da fase inicial do capitalismo perdeu seu sentido lógico e conteúdo tradicional, de forma que agora a sociedade pode exigir a aceitação de seus princípios em troca de um padrão de vida crescente. De fato, "parece fazer pouca diferença o ser a crescente satisfação das necessidades conseguida por um sistema totalitário ou não-totalitário" (MARCUSE, 1978, p.24).

Conforme Marcuse (1978, p.24), o totalitarismo não diz respeito apenas a uma coordenação política terrorista da sociedade, mas, sobretudo a uma coordenação técnicoeconômica não-terrorista. O seu principal modo de funcionamento é a manipulação das necessidades por interesses adquiridos, as quais Marcuse considera como falsas necessidades, ou seja, necessidades que são impostas exteriormente aos homens com o claro interesse em reprimilos, sendo geradas no curso do processo de trabalho a fim de mantê-lo atuante e eficaz. É através destas necessidades que a base consumista - principal elemento sustentador do sistema econômico - é perpetuada em larga escala. Logo, a liberdade individual sob a égide do capitalismo passa a se caracterizar pelo consumo e identificação com as novas necessidades, incitando a fascinação irracional que intensifica o consumo disponibilizado pelo mercado. As falsas necessidades constituem um fator importante na eliminação das tensões que poderiam romper o sistema de dominação. Em seu movimento constante em direção à crescente racionalização, o aparato tecnológico provoca o progressivo controle da subjetividade através da introjeção das falsas necessidades, atuando de forma a controlar eficazmente a liberdade subjetiva.

A satisfação das falsas necessidades pode ser tomada por algo extremamente agradável, porém, a manutenção da felicidade do indivíduo não é uma condição a ser mantida quando essa mesma felicidade serve para desenvolver a aptidão em reconhecer a moléstia do todo e aproveitar as oportunidades de cura (MARCUSE, 1978, p.26). Ou seja, por um lado, a dominação ideológica permite e até desenvolve a felicidade ilusória - mesmo que seja aquela obtida através do consumo das mercadorias - de fácil obtenção e manutenção; porém, quando essa felicidade passa a se tornar uma ameaça ao sistema, quer seja pelo desejo de se atingir a felicidade legítima, 
ou pelo desenvolvimento de necessidades que transcendam o atual sistema social, todo o aparato tecnológico é mobilizado para impedir o surgimento de tal ameaça.

Para Marcuse, as falsas necessidades são imprescindíveis à manutenção do sistema, ou seja, são as responsáveis por incentivar o consumo desnecessário e fútil, difundir ideologias, além de tolher a capacidade crítica do sujeito a fim de mais facilmente poder constituir sua subjetividade segundo parâmetros próprios. A imposição é feita pelo condicionamento através do consumo, tanto de bens materiais quanto culturais. $O$ fato de elas serem consideradas como necessárias pelos sujeitos reflete apenas a constatação de serem ou não desejáveis para as instituições sociais comuns, não importando o quanto essas falsas necessidades foram incorporadas pelos indivíduos ou independente do quanto com elas ele se identifique e obtenha, assim, satisfação; essas necessidades continuam a pertencer a uma sociedade cujo interesse dominante exige a repressão (MARCUSE, 1978, p.26)

Marcuse $(1978$, p.27) atenta para o fato de que tais necessidades repressivas são aceitas pelo indivíduo na ignorância e na derrota; porém, o reconhecimento de sua situação é requisito básico para a emancipação daqueles cuja miséria é o preço de sua satisfação. As únicas necessidades que teriam direito indiscutível à satisfação seriam aquelas destinadas à sobrevivência do indivíduo e ao seu livre desenvolvimento, isto é, aquelas das quais dependeria a satisfação de todas as outras, sublimadas ou não, tendo como propósito um fim não-exterior ao indivíduo. Porém, a distinção entre as necessidades que realmente são imprescindíveis ao indivíduo e a uma boa qualidade de vida, das que são falsas necessidades, responsáveis pelo aprisionamento da subjetividade, só pode ser realizada, em última instância, pelo próprio sujeito quando este se apresentar totalmente livre de doutrinação, manipulação ou ideologia de qualquer espécie.

Delas faz parte, por exemplo, - e aqui evidentemente falo apenas dos países industriais altamente desenvolvidos, a situação é essencialmente diferente no Terceiro Mundo - a necessidade, que já se tornou imperiosa, de, a cada ano, ou a cada dois anos comprar um carro novo, ou a necessidade de comprar um aparelho de televisão maior ou mais sofisticado, a necessidade de ficar sentado durante horas na frente desse aparelho de televisão, a necessidade de comprar todas as mercadorias que hoje são vistas como símbolos de status. São necessidades negativas, que satisfazem de fato uma necessidade que se tornou real, mas ao satisfazê-la retardam a emancipação do homem do trabalho

Periódico Horizontes - USF - Itatiba, SP - Brasil - e019037 
DOI: https://doi.org/10.24933/horizontes.v37i0.708

alienado, de todo o sistema de valores do capitalismo e trabalham contra essa emancipação (MARCUSE apud LOUREIRO, 2005, p.16).

Para Marcuse (1978, p.28), a principal característica da sociedade industrial no que se refere ao condicionamento das necessidades é o fato de que o sistema busca impedir que surjam e se desenvolvam as necessidades que exigem libertação, especialmente a libertação do que é cômodo e confortável. A própria ausência de controle físico, tal como a ação ostensiva das forças armadas, demostra a eficiência exercida pelos controles sociais personificados na ideia de razão. Marcuse considera que a congruência entre ciência, tecnologia e sociedade, no nível da experiência, está intrinsecamente enraizada no sistema capitalista, nas suas exigências e no mundo que projeta. Nesses termos, o capitalismo deixa de ser apenas um sistema econômico para tornar-se um projeto histórico.

\section{Para além do unidimensional: estética e formação}

Muito embora o livro de Marcuse que baseou nossas análises até o momento, A ideologia da sociedade industrial: o homem unidimensional, tenha sido estigmatizado por alguns como "a bíblia do pessimismo unidimensional”, o que transparece após uma detida análise é a preocupação do filósofo com a valorização de modos de comportamento que negam a unidimensionalidade e o pensamento não-crítico da sociedade industrial. Concentra-se sobretudo na abordagem crítica e dialética que possibilita o vislumbre de alternativas de libertação das condições reificadas de existência, que se corporificam sob a forma do pensamento negativo, do protesto social e da arte radical. Além disso, como atenta Kellner (2007, p.39), em uma parte negligenciada de seus textos Marcuse invoca uma fusão da arte e da tecnologia na construção de uma nova sensibilidade que viria a transformar o conceito repressivo de razão empregado através de uma base estética.

Logo, é injusto imputar ao filósofo a posição de "novo niilista", como o faz Vivas (1972), já que o movimento dialético de sua análise o leva a considerar do início ao fim de suas obras, tanto a crítica do sistema vigente, quanto à possibilidade de emergência de outra realidade. Em A ideologia da sociedade industrial: o homem unidimensional, Marcuse demonstra a possibilidade de que uma mudança qualitativa no conceito de razão poderia modificar os valores

$$
\text { Periódico Horizontes - USF - Itatiba, SP - Brasil - e019037 }
$$


de utilização e de regulação da técnica sem, porém, transformar radicalmente a sua essência. A essa transformação qualitativa da técnica, pode-se inferir uma técnica "não neutra", mas, sobretudo ambivalente, ou seja, disponível para dois caminhos distintos de desenvolvimento: o da dominação capitalista e o da realização das potencialidades ontológicas do indivíduo. Quanto ao profundo pessimismo imputado ao autor no que concerne às impossibilidades de libertação em virtude do poder do aparato técnico, a resposta já é dada na introdução da obra:

A sociedade industrial oscila do princípio ao fim, entre duas hipóteses contraditórias: 1) a de que a sociedade industrial desenvolvida seja capaz de sustar a transformação qualitativa durante o futuro previsível; e 2) a de que existem forças e tendências que podem romper essa contensão e fazer explodir a sociedade. Não creio que possa ser dada uma resposta clara. Ambas as tendências existem lado a lado - até mesmo uma dentro da outra (MARCUSE, 1978, p.18).

Para Marcuse, a possibilidade de superação do princípio do desempenho estabelecido pela sociedade industrial, situa-se na negação da totalidade social pelos grupos que se encontram fora do sistema, sugerindo que não se trata de substituir uma totalidade por outra, mas de instigar um novo princípio da realidade (SCHÜTZ, 2012, p.188). No outro polo da revolução, está a dimensão estética, a negação com base na sensibilidade. Entretanto, essa dimensão de autonomia reservada à arte encontra-se ameaçada pelo establishment, que insiste em abarcar, como o faz com as demais dimensões que contenham o gérmen da recusa e da negação, os elementos antagônicos que poderiam ameaçar o status quo da sociedade estabelecida.

A eliminação dos elementos negativos da cultura não fica restrita ao universo estético, mas abrange também a dimensão da pesquisa científica e, consequentemente, recai nos conteúdos educacionais. Tal fato se dá pela adoção dos modelos de pesquisa baseados na quantificação e mensuração característicos das ciências naturais. Dessa maneira, os conteúdos de negação contidos nas ciências humanas, que incitam um olhar mais apurado sobre o real e ressaltam a necessidade de sua transformação, são obliterados. Conforme Marcuse (1998, p.166), a educação pautada no positivismo "serve muito frequentemente para cortar a raiz da autodeterminação no espírito do homem - uma autodeterminação que significa hoje (como no passado) a desvinculação crítica do universo da experiência". O processo formativo conduzido 
pelo positivismo, que toma o objeto como uma construção técnica pré-definida, reduz as relações mundo-objeto à mera instrumentalidade, fazendo com que a noção de conhecimento que brota daí só pode ser a mera descrição em termos reificados. A partir do momento em que os valores e qualidades humanas tais como a essência do homem e a liberdade são submetidas aos modelos de pesquisa mensuráveis, "os antagonismos entre o ser e o dever ser, existência e essência, são literalmente absorvidos, mas em detrimento do dever ser e da essência" (NICOLAS, 1971, p.108).

Para Marcuse, a preservação do pensamento negativo na cultura moderna é obra principal da arte, que pela alienação consciente da esfera material tornou possível a sobrevivência de um âmbito que apontava tanto para a valorização da subjetividade política, quanto para a crítica à realidade. É no contato com a arte, sobretudo a partir de uma educação estética, que surge um processo formativo guiado essencialmente pela razão crítica. Nas palavras de Maar (2003, p.63), é no conceito de resistência que reside o espaço para uma dialética da emancipação: a relação com a realidade, apreendida como contradição, ressalta a necessidade de não se limitar à adaptação, mas recorrer à resistência contra a adaptação no que significa a imposição da realidade como algo meramente exterior, não apreendida numa relação de experiência. Nesses termos, a razão crítica compreende uma relação ambígua com a realidade, enquanto adaptação e enquanto inadequação. A razão é essencialmente negativa: "ela se torna o que realmente é pela relação com o que não é" (MAAR, 2003, p.63), sendo que é nesse vai-evem dialético que é possível atingir o objetivo de realizar a essência humana.

A dimensão estética representa para Marcuse o obrigatório movimento da dialética que se reflete mais tarde na própria sociedade: é através da concepção de arte e cultura que podemos nos deparar diretamente com o movimento dialético de negação e afirmação, tese a antítese, que perpassam todas as suas obras: por um lado, a cultura e a arte desempenharam (e ainda continuam a desempenhar) um importante papel na formação das forças de dominação; porém, ao mesmo tempo, elas representam também as possibilidades de libertação dessas mesmas forças. A teoria estética desenvolvida por Marcuse é, portanto, uma teoria dialética onde o filósofo busca articular no interior da argumentação as contradições, ambiguidades e ambivalências da arte, criticando os aspectos dominadores e articulando os libertadores.

No processo formativo conduzido pela estética, a arte guarda a tensão latente com a realidade porque a nega por princípio; no entanto, enquanto utiliza o material compartilhado 
com a realidade, ela a confirma em outros planos como conhecimento dessa mesma realidade. A atitude crítica da arte é, portanto, aquela capaz de penetrar nos fundamentos desse conflito, traduzindo a tensão entre realidade e representação para extrair do material estético o material histórico. Na consciência das contradições sociais, a estética enquanto parâmetro da formação permite ao indivíduo o surgimento de uma consciência objetiva. Pois a arte não consiste apenas em uma expressão meramente subjetiva, no sentido de traduzir a realidade a uma mera idiossincrasia. Para Marcuse, a projeção na objetividade é um requisito básico de toda a obra de arte autêntica: sua ação permite reverter a percepção objetificada com que o sujeito é levado à introjetar o mundo.

Para Kellner (2015, p.44), a filosofia marcuseana é embasada essencialmente na dialética entre emancipação e dominação, de maneira que o homem e a sociedade estabelecida são sempre contrastados com uma sociedade ideal liberada, assim como o pensamento unidimensional aparece em contraste com o pensamento crítico e dialético. Kellner propõe ainda que interpretemos o termo "unidimensional" como um conceito que descreve um estado de coisas que está em conformidade com o pensamento e o comportamento vigente, no qual falta a dimensão crítica, assim como alternativas e potencialidades que transcendem a sociedade existente.

Esta perspectiva abre espaço para uma dialética da emancipação no quanto a relação que o indivíduo mantém com a realidade se dá no duplo movimento de adaptação à realidade, mas também na necessidade de não se limitar à adaptação, mas recorrer à resistência contra a adaptação enquanto mera imposição de um determinado estado de coisas. Nesses termos é preciso considerar, conforme Maar (1995, p.63), que a racionalidade envolve "segundo a perspectiva crítica uma relação ambígua com a realidade, enquanto 'adaptação' e enquanto 'inadequação'”. A razão na teoria crítica aparece essencialmente como razão negativa, na qual o método da educação crítica aparece como "dialética negativa", na qual as coisas se tornam o que são pelo confronto direto com aquilo que não são:

$\mathrm{Na}$ equação Razão $=$ Verdade $=$ Realidade, que reúne os mundos subjetivo e objetivo, numa realidade antagônica, a Razão é o poder subversivo, o 'poder do negativo' que estabelece, como Razão teórica e prática, a verdade para os homens e as coisas - isto é, as condições nas quais os homens e as coisas se tornam o que realmente são (MARCUSE, 1978, p.125). 
A educação, na medida em que leva a cabo a mediação de uma visão do homem e do mundo, promove também um conceito de razão que, na maioria das vezes, se resume à razão formalizada, ou seja, aquela predominante na civilização ocidental. Ela aparece na interpretação da pedagogia como embasada em processos de quantificação e na desvinculação da formação da totalidade em que se insere. Em uma vinculação direta com as ciências exatas, esse processo acarreta uma série de consequências desastrosas para a educação, das quais podemos citar a perda da dimensão histórica de experiência. Conforme Dalbosco (2014, p.1031), a transposição desse modelo para a educação torna-se extremamente problemático porque ele "objetiva (mensura) aquilo que por princípio não deve ser objetivado, isto é, o próprio ser humano".

Nesses termos cabe voltar-nos para o legado deixado pela teoria crítica de Marcuse. Enquanto aponta para a necessidade de recuperar a dimensão negativa da razão, a filosofia marcuseana também nos permite inferir um conceito de educação crítica que se pauta pela contraposição à forçosa imposição da realidade como aceitação acrítica do status quo. Somente no cultivo de disposições que se contrapõe à fragmentação e a desvinculação do universo histórico, e que revelam a lógica do positivismo na educação, podemos projetar uma racionalidade, que em seu cultivo ampliado, aparece como multidimensional.

\section{Considerações finais}

Se por um lado o livro A ideologia da sociedade industrial foi atacado como uma obra profundamente pessimista, caracterizada como parte da fase de arrefecimento dos ideais de Marcuse, ao empreendermos uma leitura crítica e detida dessa obra nos deparamos como a afirmação de necessidade de mudança e a abertura de possibilidades concretas de construção de uma realidade alternativa. No resgate do pensamento negativo contido na dimensão estética, a razão pode recuperar o seu caráter de negação e, assim, conduzir à emancipação. Ou seja, somente podemos nos referir à emancipação das condições existenciais repressivas quando retomamos a ideia de razão como uma construção conjunta tanto de Logos como de Eros.

Se a ciência, ao pautar-se unicamente sob o viés positivista, origina uma técnica que aprisiona os indivíduos em um estado de servidão, somente na recuperação da razão negativa é possível resgatar uma noção técnica capaz direcionada para a tarefa da pacificação da existência.

$$
\text { Periódico Horizontes - USF - Itatiba, SP - Brasil - e019037 }
$$


Logo, em Marcuse a transformação da realidade somente pode ser concretizada quando se considera a dinâmica dialética entre positivo e negativo, tal qual é realizada pela dimensão estética da arte. Nesses termos, ressalta-se a importância da permanência da crítica e da contradição como parte de um conceito de formação que é, em suma, essencialmente político, pois se coloca na contramão da unidimensionalidade quando evoca uma razão multidimensional.

Com a inserção cada vez maior do mercado no âmbito educacional e o agravamento das crises educacionais dos últimos tempos, cabe colocar em pautar a necessidade de uma educação crítica que se contraponha a esse panorama. Entendemos pelo exposto até aqui que a teoria crítica de Marcuse nos fornece importantes elementos teóricos para uma teoria crítica da educação, pois aponta não só para a necessidade de pensarmos processos que se contraponham a aceitação da realidade em termos passivos, mas também nos permite vislumbrar possibilidades de transformação dessa mesma realidade.

\section{Referências}

DALBOSCO, C. A. Pesquisa educacional e experiência humana na perspectiva hermenêutica. Cadernos de pesquisa, v.44, n.154, p.1028-1051, out./dez. 2014.

FEENBERG, A. Fenomenologia de Marcuse: lendo o capítulo seis de o homem unidimensional. In: CONGRESSO INTERNACIONAL FANTASIA E CRÍTICA, 1., 2012, Belo Horizonte. Caderno de textos. Belo Horizonte: ABRE, p.140-152, 2012.

KELLNER, D. Introduction: Marcuse, art and liberation. In: KELLNER, D (Org.). Art and liberation: collected papers of Herbert Marcuse Vol. 4. New York: Routledge, 2007, p. 1-70.

KELLNER, D. Reflexões sobre Herbert Marcuse no quinquagésimo aniversário de publicação de One-dimensional man. Artefilosofia, n. 18, p.35-49, 2015.

LOUREIRO, I. M. Herbert Marcuse: anticapitalismo e emancipação. Trans/For/Ação, São Paulo, n.28, p.7-20, 2005.

MAAR, L. M. Educação crítica, formação cultural e emancipação política na Escola de Frankfurt. In: PUCCI, B. (Org.). Teoria crítica e educação: a questão da formação cultural na Escola de Frankfurt. Rio de Janeiro, EDUFISCAR, 1995, p. 59-82.

MARCUSE, H. Razón y revolución: Hegel y el surgimiento de la teoria social. Barcelona: Atalaya, 1972. 
MARCUSE, H. A ideologia da sociedade industrial: o homem unidimensional. Trad. Giasone Rebuá. Rio de Janeiro: Zahar Editores, 1978.

MARCUSE, H. Comentários para uma redefinição de cultura. In: MARCUSE, H. Cultura a sociedade vol. II. Trad. Wolfgang L. Maar, Isabel M. Loureiro, Robespierre de Oliveira. São Paulo: Paz e Terra, 1998, p. 153-175.

NICOLAS, A. Marcuse ou a busca de um universo transprometeico. Trad. Franco de Sousa. Lisboa: Estúdios Cor, 1971.

PISANI, M. M. Marxismo e psicanálise no pensamento de Herbert Marcuse: uma polêmica. Revista Mal-estar e Subjetividade, Fortaleza, v.4, n.1, p.23-64, mar. 2004.

SCHÜTZ, R. O deslocamento do lugar social da negação em Herbert Marcuse. Argumentos, ano 4, n.8, p.188-198, 2012.

VIVAS, E. Marcuse em julgamento. Trad. Hélio Polvora. Rio de Janeiro: Edições Bloch, 1972.

Recebido em julho de 2018.

Aprovado em março de 2019. 